\title{
Improvements in the cervical angle and anthropometric distances using elasticum suspension
}

\author{
Seong Kee Kim ${ }^{1,2}$, Kun Hwang ${ }^{2}$, Hun Kim², Young Rok Kim², Yeop Na \\ ${ }^{1}$ Dr Kim's Aesthetic Surgical Plastic Clinic, Seoul 06025, South Korea. \\ ${ }^{2}$ Department of Plastic Surgery, Inha University School of Medicine, Incheon 22332, South Korea.
}

Correspondence to: Dr. Kun Hwang, Department of Plastic Surgery, Inha University School of Medicine, 27 Inhang-ro, Jung-gu, Incheon 22332, South Korea. E-mail: jokerhg@inha.ac.kr

How to cite this article: Kim SK, Hwang K, Kim H, Kim YR, Na Y. Improvements in the cervical angle and anthropometric distances using elasticum suspension. Plast Aesthet Res 2016;3:384-9.

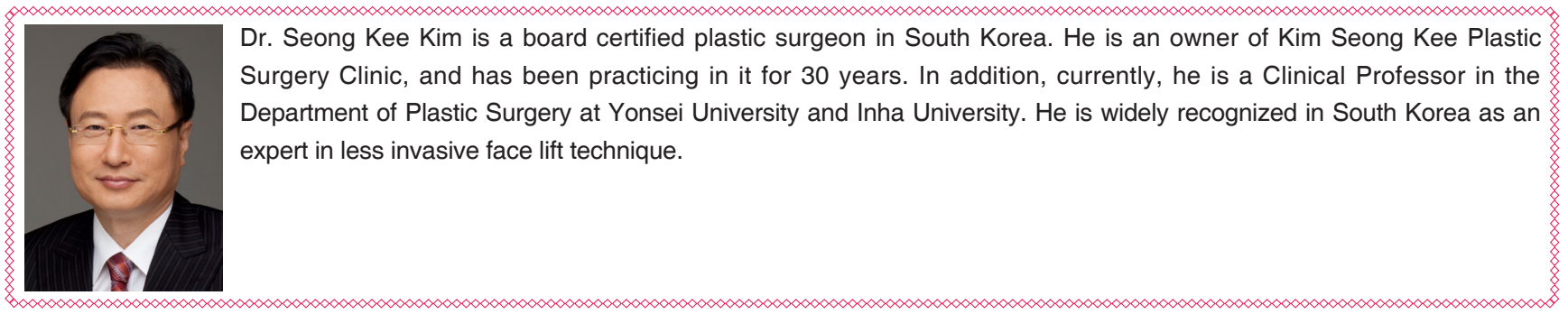

Article history:

Received: 17-10-2016

Accepted: 02-11-2016

Published: 23-12-2016

Key words:

Rhytidoplasty,

rejuvenation,

anthropometry

\begin{abstract}
ABSTRAC T
Aim: This study aims to characterize the effects of elastic facelifts using the elasticum suspension technique on the cervical angle and anthropometric distances. Methods: Forty-six patients underwent surgery. Two 4-5 mm incisions a few centimetres apart were made at sideburn. Through blunt dissection, the deep temporal fascia was approached. An elastic thread (Elasticum $^{\circledR}$ ) was anchored to this fascia. A $1.0 \mathrm{~cm}$ incision was made just in front of the earlobe. The elastic thread was anchored to the tympanoparotid fascia. Jano needle was passed under the skin surface, as determined by the depth mark of the needle along the cervicomandibular angle, and the elastic threads were looped around the contralateral tympanoparotid fascia. Standard lateral photographs were taken and evaluated. Results: The elasticum suspension significantly decreased the cervical angle $(P<0.001,-5.5 \pm 9.8 \%)$. This procedure significantly decreased the distance from the gonion-gnathion to the labiale inferioris (Gn-Li) $(P<0.001,-18.4 \pm 25.5 \%)$. The ratio of the distance from $\mathrm{Gn}$ to the cervical point $(\mathrm{Gn}-\mathrm{C})$ to $\mathrm{Gn}-\mathrm{Li}$ increased significantly $(P$ $<0.001,62.8 \pm 85.8 \%)$ and the ratio of the distance from $\mathrm{C}$ to the visible thyroid cartilage (C-T) to $\mathrm{Gn}-\mathrm{C}$ decreased significantly $(P=0.007,-7.1 \pm 45.2 \%)$. Conclusion: Elasticum suspension may be a satisfactory minimally invasive method for facelifts, brow lifts, and neck lifts.
\end{abstract}




\section{INTRODUCTION}

Most patients who desire to undergo facial rejuvenation want their skin in the mandible and zygomatic regions to be pulled cranially without a visible scar from the facelift. ${ }^{[1]}$ In order to fulfil these goals, the S-lift followed by minimal access cranial suspension (MACS) lift has been developed and put into practice. ${ }^{[1-3]}$ The MACS lift requires a smaller incision, less dissection, and less operating time than classical facelift operations. Although it has the advantage of a shorter recovery time, it nonetheless requires at least 2 or 3 weeks before patients can return to social activities. Recently, the elastic facelift technique has been introduced. Using a straight needle and elastic thread fixed at the midpoint of the needle, lower face lifts and neck lifts have been performed. ${ }^{[4,5]}$ The aim of this study is to characterize the effects of the elastic facelift procedure using elasticum suspension on the cervical angle and anthropometric distances.

\section{METHODS}

\section{Patients}

A total of 46 patients (4 males, 42 females) were operated on between July 2013 and May 2015. Their mean age was $53.9 \pm 10.9$ years (range $33-79$ years). Most of the patients were in their 40s (12), 50s (15), and 60s (11) [Table 1].

\section{Operative technique}

Preoperatively, a marking pen was used to indicate the points where the elastic thread was to be passed and turned toward the entry site of the thread; these points were located about $3.0 \mathrm{~cm}$ and $1.5 \mathrm{~cm}$ from the preauricular fold, on and superior to a line running from below the earlobe to the lower part of the alar nasi. For the neck lift, 2 lines were marked from the earlobe junction. The 1 st line was to a point near the angle of the mandible, and the 2 nd line inferior to the 1st for making a loop [Figure 1].

In order to perform an elastic facelift without skin excision, two 4-5 mm incisions a few centimetres apart were made in the sideburn area. Through blunt dissection, the deep temporal fascia was approached. An elastic thread (Elasticum ${ }^{\circledR}$ EP3,5 USP 0 Jano needle $^{\circledR} 115 \mathrm{~mm}$, Korpo SRL, Genova, Italy) was anchored to this fascia. In order to perform an elastic neck lift without skin excision, a $1.0 \mathrm{~cm}$ incision was made just in front of the earlobe. The elastic thread was anchored to the tympanoparotid fascia (Lore's fascia). ${ }^{[6]}$

The Jano needle was passed $5 \mathrm{~mm}$ under the skin surface, as determined by the depth mark of the
Table 1: Age distribution of patients

\begin{tabular}{lc}
\hline Age (years) & Number \\
\hline $30-39$ & 4 \\
$40-49$ & 12 \\
$50-59$ & 15 \\
$60-69$ & 11 \\
$70-79$ & 4 \\
Total $(53.9 \pm 10.9)$ & 46 \\
\hline
\end{tabular}

needle along the cervicomandibular angle, and the elastic threads were looped around the contralateral Lore's fascia, but were not tied. The same needle was passed along a $1.0 \mathrm{~cm}$ parallel line below the cervicomandibular angle. Returning to the initial Lore fascia, the elastic thread was tied under maximum tension. During passage of the Jano needle, slight upand-down movements of the needle tip allowed the operator to ensure that the pathway of the needle was not too superficial.

In both elastic facelifts and elastic neck lifts, the excess skin could be excised in order to prevent tissue from getting jammed. Just after anchoring, patients were checked for skin dimples, and when present, filler or fat injections were performed [Figure 2].

\section{Lateral photographs}

Lateral photographs were taken in the standard manner preoperatively, 2 weeks and 6 months postoperatively.

The patients sat $90 \mathrm{~cm}$ from the lens (EFS18-55 mm, Canon EOS600D, Canon, Tokyo, Japan). Flashes (FOMEX D400, Fomex, Seoul, Korea) on both sides were synchronized (Shutter speed: 1/100 s, ISO: 200).

\section{Anthropometric measurements}

The preoperative and postoperative profile views were

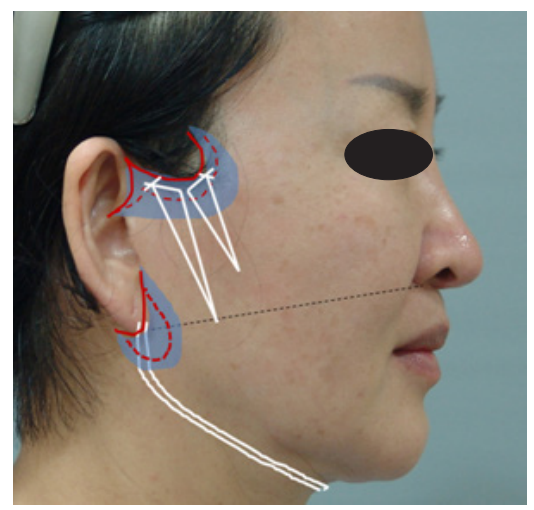

Figure 1: Preoperative design. Red solid lines: skin incision; red dotted lines: extent of skin excision; blue area: extent of dissection white lines: passages and knots of Elasticum ${ }^{\circledR}$. Note the lowermos point of elasticum suspension should be superior to the line from below the earlobe to the lower part of the alar nasi to avoid the parotid duct injury 

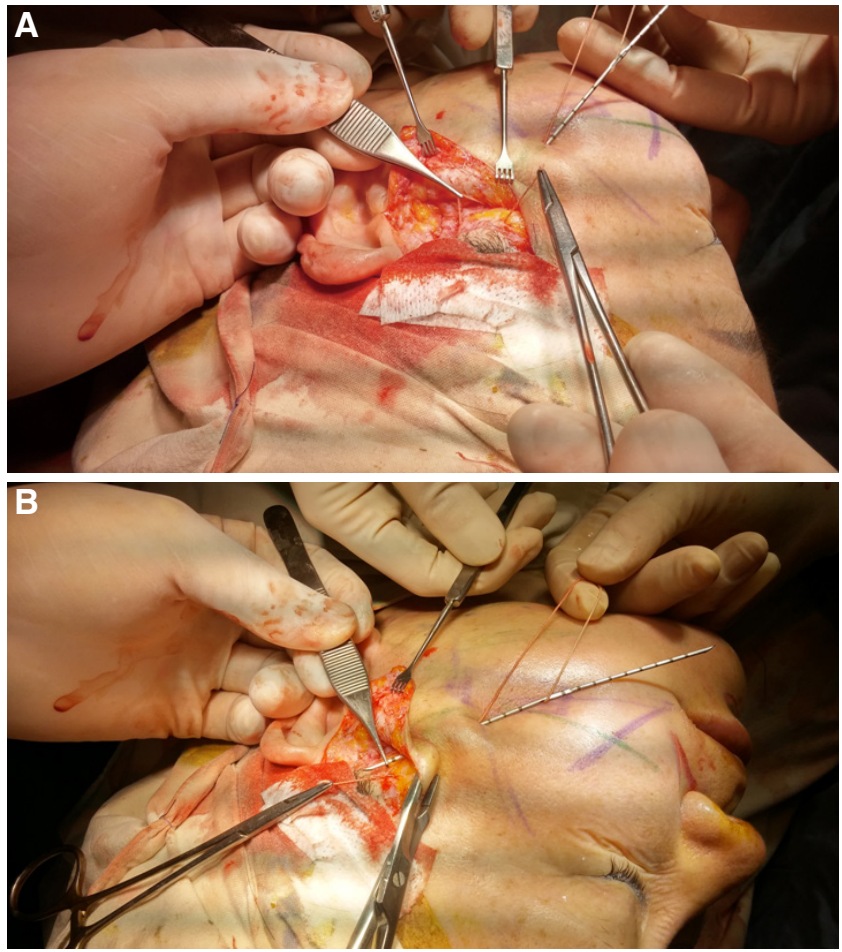

Figure 2: Operative technique. (A) After anchoring to the deep temporal fascia, two-tipped atraumatic needle (Jano needle) travels through the deep subcutaneous tissue. The needle must not be extracted completely. Once it has been pulled halfway out, the thread is pulled through. Depth marks on the shaft of the needle indicate how much of the tip remains in the tissue (about $1 \mathrm{~cm}$ or $1 / 2 \mathrm{~cm}$ from the surface of the skin). (B) The posterior tip of needle now become anterior and travels back toward the temporal region through the deep subcutaneous tissue until it reaches the point where the thread enters the deep temporal fascia. The elastic thread is then knotted under traction

evaluated by identifying the glabella $(G)$, pogonion $(\mathrm{Pg})$, menton $(\mathrm{M})$, gonion-gnathion $(\mathrm{Gn})$, cervical point (C) and visible thyroid cartilage (T) [Figure 3$]^{[7]}$

The following three anthropometric tangents were drawn: (1) glabella to pogonion ( $\mathrm{G}$ to $\mathrm{Pg}$ ); (2) menton to cervical point ( $M$ to $C$ ); (3) cervical point to visible thyroid cartilage ( $C$ to $T)$.

Two angles were measured: (1) mental angle (MA): an angle formed by a line connecting $\mathrm{G}$ and $\mathrm{Pg}$ and a line from $M$ to $C$ (tangent to the submentum). The $\mathrm{Gn}$ point was identified at the intersection of the G-Pg line and the $\mathrm{M}-\mathrm{C}$ line; (2) cervical angle (CA): an angle formed by a line from $M$ to $C$ and a line from $C$ to T. Since neck flexion might influence the cervical angle, measured cervical angle (mCA) was converted to corrected cervical angle (cCA) by fixing the submental-sternocleidomastoid angle (SSA) at $90^{\circ} .{ }^{[7]}$ Thereafter, cCA could be calculated as mCA plus $90^{\circ}$ minus SSA (cCA $\left.=m C A+90^{\circ}-\mathrm{SSA}\right)$ [Figure 4].

Three distances were measured in relation to ear
Figure 3: Measured distances and angles. Distance from the Goniongnathion $(\mathrm{Gn})$ to cervical point $(\mathrm{C})$ $(\mathrm{Gn}-\mathrm{C})$, from $\mathrm{G}$ to labiale inferioris (Li) $(\mathrm{Gn}-\mathrm{Li})$, from $\mathrm{C}$ to the visible thyroid cartilage $(T)(C-T)$. Mental angle (MA): an angle formed by a line connecting glabella $(G)$ and pogonion $(\mathrm{Pg})$ and a line from the menton (M) to C. Cervical angle (CA): an angle formed by a line from the $M$ to $C$ and a line from $C$ to $T$

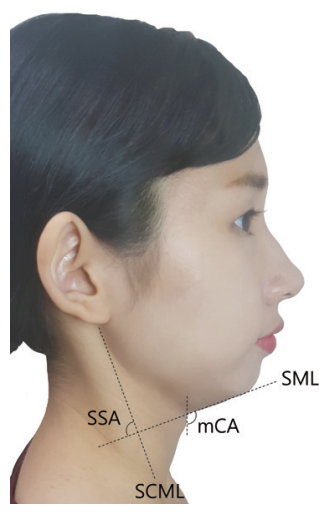

Figure 4: Calculating $c C A$. $\mathrm{cCA}=\mathrm{mCA}+90^{\circ}-\mathrm{SSA} \cdot \mathrm{mCA}$ : measured cervical angle; SSA: submental-sternocleidomastoid angle; SML: submental line; SCML: sternocleidomastoid line (anterior border of SCM)

Table 2: Operated patients according to the skin excision

\begin{tabular}{llc}
\hline Operation type & Region & Number \\
\hline SE & Face & 22 \\
& Neck & 9 \\
& Face and neck & 3 \\
SO & Subtotal & 34 \\
& Face & 7 \\
& Neck & 2 \\
& Face and neck & 3 \\
Total & Subtotal & 12 \\
\hline
\end{tabular}

SE: suspension and excision; SO: suspension only

length: (1) distance from gonion-gnathion to cervical point $(\mathrm{Gn}-\mathrm{C})$; (2) distance from gonion-gnathion to the labiale inferioris ( $\mathrm{Li})(\mathrm{Gn}-\mathrm{Li})$; (3) distance from cervical point to visible thyroid cartilage (C-T).

Two ratios were calculated: $\mathrm{Gn}-\mathrm{C} / \mathrm{Gn}-\mathrm{Li}$ ratio and C-T/ $\mathrm{Gn}-\mathrm{C}$ ratio.

\section{RESULTS}

Among the 46 patients who were operated on, 34 patients [the suspension and excision (SE) group] underwent elasticum suspension with skin excision (face, 22; neck, 9; face and neck, 3). However, 12 patients underwent elasticum suspension without skin excision [suspension-only (SO) group: face, 7; neck, 9; face and neck, 3] [Table 2]. 
Table 3: Comparison of preoperation and postoperation measurements (mean \pm SD)

\begin{tabular}{llcccc}
\hline & & Preoperation & Postoperation & Delta (\%) & P-value \\
\hline \multirow{2}{*}{ Angle $\left(^{\circ}\right)$} & Mental angle & $97.2 \pm 9.4$ & $96.9 \pm 9.1$ & $0.1 \pm 9.0$ & 0.831 \\
& Cervical angle & $135.1 \pm 15.6$ & $126.9 \pm 14.6$ & $-5.5 \pm 9.8$ & $<0.001$ \\
\multirow{2}{*}{ Distance } & Gn-C & $56.8 \pm 17.4$ & $62.1 \pm 15.3$ & $19.2 \pm 47.1$ & 0.125 \\
& Gn-Li & $52.5 \pm 25.6$ & $38.2 \pm 9.5$ & $-18.4 \pm 25.5$ & $<0.001$ \\
\multirow{2}{*}{ Ratio } & G-T & $36.3 \pm 15.0$ & $33.0 \pm 11.4$ & $0.2 \pm 41.0$ & 0.243 \\
& Gn-C/Gn-Li & $1.2 \pm 0.5$ & $1.6 \pm 0.2$ & $62.8 \pm 85.8$ & $<0.001$ \\
\hline
\end{tabular}

Delta $=($ preoperation value - postoperation value)/pre-operation value. Gn: gonion-gnathion; C: cervical point; Li: labialeinferioris; T: thyroid cartilage

Table 4: Angle changes and distance changes in SE group and SO group (mean \pm SD)

\begin{tabular}{llccc}
\hline & & SE & SO & P-value \\
\hline \multirow{2}{*}{$\Delta$ Angle } & Mental angle & $0.1 \pm 9.8$ & $0.2 \pm 6.8$ & 0.283 \\
& Cervical angle & $-5.9 \pm 10.0$ & $-4.6 \pm 9.5$ & 0.701 \\
\multirow{2}{*}{ Distance } & Gn-C & $9.2 \pm 43.0$ & $47.8 \pm 48.2$ & 0.386 \\
& Gn-Li & $-8.4 \pm 20.4$ & $-46.8 \pm 15.1$ & 0.296 \\
$\Delta$ Ratio & C-T & $4.8 \pm 45.2$ & $-12.6 \pm 22.0$ & 0.027 \\
& Gn-C/Gn-Li & $21.7 \pm 41.6$ & $179.4 \pm 69.7$ & 0.037 \\
\hline
\end{tabular}

SE: suspension and excision; SO: suspension only; Gn: gonion-gnathion; C: cervical point; Li: labialeinferioris; T: visible thyroid cartilage; $\Delta$ Angle: angle change ratio; $\Delta$ Distance, distance change ratio; $\Delta$ Ratio: ratio change rate

The MA did not change significantly after the operation $\left(97.2 \pm 9.4^{\circ}\right.$ preoperatively vs. $96.9 \pm 9.1^{\circ}$ postoperatively; $P=0.831$, paired $t$-test). The angle change ratio $(A C R)$ was $0.1 \pm 9.0 \%$. The ACR of the MA did not differ significantly between the SE group $(0.1 \pm 9.8 \%)$ and the SO group $(0.2 \pm 6.8 \%)(P=0.283$, paired $t$-test) [Tables 3 and 4 ].

The CA significantly decreased $(P<0.001$, paired $t$-test) after the operation $\left(135.1 \pm 15.6^{\circ}\right.$ preoperatively $v s$. $126.9 \pm 14.6^{\circ}$ postoperatively). The ACR of the CA was $-5.5 \pm 9.8 \%$. The ACR of the CA likewise did not differ significantly $(P=0.707$, paired $t$-test) between the SE group $(-5.9 \pm 10.0 \%)$ and the SO group $(-4.6 \pm 9.5 \%)$ [Tables 3 and 4].

The $\mathrm{Gn}-\mathrm{C}$ distance did not differ significantly after the operation (56.8 $\pm 17.4 \%$ preoperatively vs. $62.1 \pm 15.3 \%$ postoperatively; $P=0.125$, paired $t$-test). The distance change ratio (DCR) was $19.2 \pm 47.1 \%$. The DCR of Gn-C did not differ significantly $(P=0.083$, paired $t$-test $)$ between the SE group $(9.2 \pm 43.0 \%)$ and the SO group $(47.8 \pm 48.2 \%)$ [Tables 3 and 4 ].

The Gn-Li distance decreased significantly $(52.5 \pm 25.6 \%$ preoperatively vs. $38.2 \pm 9.5 \%$ postoperatively; $P<$ 0.001 , paired $t$-test). The DCR was $-18.4 \pm 25.5 \%$, and the DCR of the Gn-Li distance did not differ significantly $(P=0.296$, paired $t$-test) between the SE group $(-8.4 \pm 20.4 \%)$ and the SO group $(-46.8 \pm 15.1 \%)$ [Tables 3 and 4 ].
The C-T distance did not differ significantly (36.3 $\pm 15.0 \%$ preoperatively vs. $33.0 \pm 11.4 \%$ postoperatively; $P=0.243$, paired $t$-test), and the DCR was $0.2 \pm 41.0 \%$. The DCR of the C-T distance was significantly greater $(P=0.027$, paired $t$-test $)$ in the SE group $(4.8 \pm 45.2 \%)$ than in the SO group (-12.6 $\pm 22.0 \%$ ) [Tables 3 and 4 ].

The $\mathrm{Gn}-\mathrm{C} / \mathrm{Gn}$-Li ratio was significantly greater $(P<$ 0.001 , paired $t$-test) after the operation $(1.6 \pm 0.2 \%)$ than before the operation $(1.2 \pm 0.5 \%)$, and the ratio change rate (RCR) was $62.8 \pm 85.8 \%$. The RCR of the $\mathrm{Gn}-\mathrm{C} / \mathrm{Gn}-\mathrm{Li}$ ratio was significantly greater $(P=$ 0.037 , paired $t$-test) in the SO group (179.4 $\pm 69.7 \%)$ than the SE group $(21.7 \pm 41.6 \%)$ [Tables 3 and 4 ].

The C-T/Gn-C ratio was significantly lower $(P=$ 0.007 , paired $t$-test) postoperatively $(0.5 \pm 0.2 \%)$ than preoperatively $(0.7 \pm 0.3 \%)$, and the RCR was $-7.1 \pm 45.1 \%$. The RCR of the C-T/Gn-C ratio was significantly higher in the SE group $(3.6 \pm 47.4 \%)$ than in the SO group $(-37.4 \pm 15.2 \%)$ [Tables 3 and 4 ].

Two complications were observed. In one patient, paralysis of the frontal branch of the facial nerve was noticed. The thread was removed on postoperative day (POD) 2 , and the palsy exhibited recovery on POD 7. In the other case, a sialocele occurred due to Stenson's duct folding caused by making the knot under too much tension. The thread was loosened on POD 3, and the swelling had subsided on POD 7. 

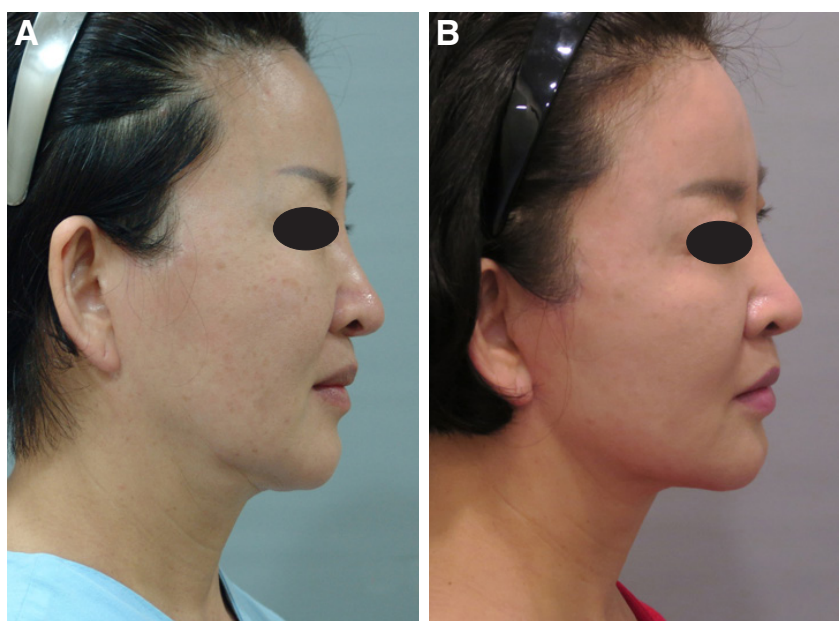

Figure 5: Preoperative (A) and postoperative 3 years (B) photographs of a 64-year-old woman who had elastic face lift and neck lift with skin excision
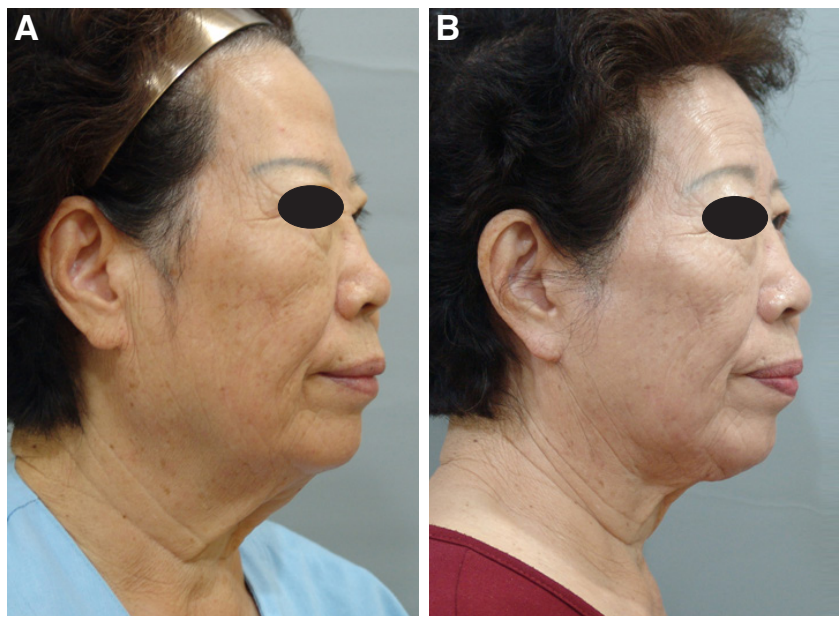

Figure 7: Preoperative (A) and postoperative 3 years (B) photographs of an 80-year-old woman who had elastic neck lift with skin excision

\section{Case 1}

A 64-year-old woman had elastic face lift and neck lift with skin excision. At 3 years postoperatively, mental angle (from $89.3^{\circ}$ to $83.5^{\circ}$ ), and cervical angle (from $114.4^{\circ}$ to $112.3^{\circ}$ ) decreased. The Gn-C (from 55.5\% to $69.8 \%$ of ear length), Gn-Li (from $55.9 \%$ to $59.3 \%$ of ear length), and C-T (from $42.3 \%$ to $45.9 \%$ of ear length) increased [Figure 5].

\section{Case 2}

A 52-year-old woman had elastic face lift and neck lift with skin excision. At 2 years postoperatively, mental angle (from $107.3^{\circ}$ to $77.6^{\circ}$ ) and cervical angle (from $154.1^{\circ}$ to $99.0^{\circ}$ ) decreased. The Gn-C (from $31.2 \%$ to $64.0 \%$ of ear length), Gn-Li (from $46.3 \%$ to $66.4 \%$ of ear length), and C-T (from $29.9 \%$ to $33.4 \%$ of ear length) increased [Figure 6].
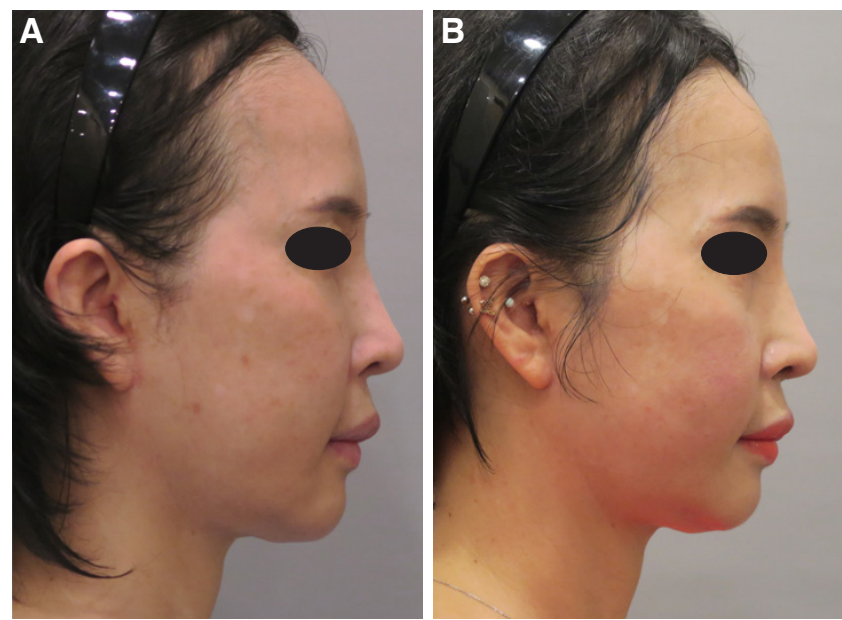

Figure 6: Preoperative (A) and postoperative 2 years (B) photographs of a 52-year-old woman who had elastic face lift and neck lift with skin excision

\section{Case 3}

A 80-year-old woman had elastic neck lift with skin excision. At 3 years postoperatively, mental angle (from $86.3^{\circ}$ to $73.7^{\circ}$ ), and cervical angle (from $144.7^{\circ}$ to $123.7^{\circ}$ ) decreased. The Gn-C (from $29.2 \%$ to $48.3 \%$ of ear length), Gn-Li (from $51.6 \%$ to $63.8 \%$ of ear length) increased. The C-T decreased (from $37.9 \%$ to $27.1 \%$ of ear length) [Figure 7 ].

\section{DISCUSSION}

Recently, Kang et al. ${ }^{[8,9]}$ performed an elastic lift using Elasticum $^{\circledast}$ (Korpo SRL) and a two-tipped long needle (Jano needle). He evaluated its efficacy by rating skin laxity (6 grades of sagging and laxity) using a skin scanner. For the facelifts, the preoperative and 3 -month postoperative median skin laxity scores were $5(3-6)$ and $3(2-4)$ respectively. For the neck lifts, the median skin laxity grade score was 5 (4-5) preoperatively and 3 at 3 months postoperatively.

Also, Stringer et al. ${ }^{[10]}$ assessed the surface anatomy of 98 parotid ducts using ultrasonography. In most individuals, the duct is better represented as lying within $1.5 \mathrm{~cm}$ of the middle half of a line between the lower border of the tragus and the angle of the mouth. Thereafter, we designed the lowermost point of elasticum suspension superior to the line from below the earlobe to the lower part of the alar nasi to avoid the parotid duct injury.

We tried to standardize the pre and postoperative pictures, however, neck flexion cannot be same. Since neck flexion might influence the cervical angle, mCA was converted to cCA by fixing the SSA at $90^{\circ}$ as Ellanbogen and Karlen suggested. ${ }^{[7]}$ Thereafter, cCA 
can be calculated as $\mathrm{mCA}$ plus $90^{\circ}$ minus SSA (cCA $=$ $\mathrm{mCA}+90^{\circ}$ - SSA) [Figure 4].

In our preoperative and postoperative measurements, elasticum suspension significantly decreased the CA $(P<0.001,-5.5 \pm 9.8 \%)$. This procedure significantly decreased the $\mathrm{Gn}-\mathrm{Li}$ distance $(P<0.001,-18.4 \pm$ $25.5 \%)$. The $\mathrm{Gn}-\mathrm{C} / \mathrm{Gn}-\mathrm{Li}$ ratio increased significantly $(P<0.001,62.8 \pm 85.8 \%)$, while the $\mathrm{C}-\mathrm{T} / \mathrm{G}$-C $\mathrm{C}$ ratio decreased significantly $(P=0.007,-7.1 \pm 45.2 \%)$ [Table 3].

In the 46 patients that were operated on, suspension was performed with skin excision in 34 patients who had skin redundancies, whereas 12 patients underwent suspension without skin excision. The purpose of skin excision was not to pull the skin, but to prevent tissue from getting jammed. Minor jammed soft tissues were found to have subsided spontaneously within a few weeks.

For three parameters (CA, Gn-C, and $\mathrm{Gn}-\mathrm{Li}$ ), no significant differences were found between the SE group and SO group. Regarding the Gn-C/Gn-Li ratio, the RCR was significantly higher in the SO group $(179.4 \pm 69.7 \%)$ than the SE group $(21.7 \pm 41.6 \%)$. For the C-T/Gn-C ratio, the RCR was significantly higher in the SE group $(3.6 \pm 47.4 \%)$ than the SO group $(-37.4 \pm 15.2 \%)$ [Table 4$]$.

The advantages of the elasticum suspension are as follows. First, Elasticum ${ }^{\circledR}$ does not cut into the tissues. It is composed of a silicone core and surrounding braided polyester, and the braided polyester effectively acts as a nidus for collagen and elastin to develop, similarly to a neoligament. ${ }^{[11]}$ Second, it has the same consistency as the subcutaneous tissue, and is not palpable after placement. Third, the depth of the thread can be referenced by the depth mark on the Jano needle.

Based on our results, it appears that the elasticum suspension technique may be a satisfactory minimally invasive method for neck lifts. Elasticum suspension can be performed together with submental and superficial jowl liposuction. If necessary, a perioral fat graft could be performed. This technique could be also applied to the lifting the upper lip or breast, as well as scar revisions.

\section{Acknowledgments}

We thank Miss Seong Kyung Yoo, BS, for her help in measurement and being object of Figure 4 .

\section{Financial support and sponsorship}

This study was supported by Inha University (INHAResearch Grant).

\section{Conflicts of interest}

There are no conflicts of interest.

\section{Patient consent}

Informed consent was obtained from paients.

\section{Ethics approval}

All procedures performed in studies involving human participants were in accordance with the ethical standards of the institutional and/or national research committee and with the 1964 Helsinki declaration and its later amendments or comparable ethical standards.

\section{REFERENCES}

1. Tonnard P, Verpaele A, Monstrey S, Van Landuyt K, Blondeel P, Hamdi M, MattonG. Minimal access cranial suspension lift: a modified S-lift. Plast Reconstr Surg 2002;109:2074-86.

2. Saylan Z. Liposhifting instead of lipofilling: treatment of postlipoplasty irregularities. Aesthet Surg J 2001;21:137-41.

3. Fulton JE, Saylan Z, Helton P, Rahimi AD, Golshani M. The S-lift facelift featuring the U-suture and $\mathrm{O}$-suture combined with skin resurfacing. Dermatol Surg 2001;27:18-22.

4. Capurro S, Rava C, Berlanda M. Elastic MACS and neck lift in men. CRPUB Med Video J [Internet]. 2010. Available from: http://www. crpub.org/index.php?option $=$ com_k2\&view $=$ item\&id $=52: 10$-elasticmacs-and-neck-lift-in-men\&Itemid=114. [Last accessed on 2016 Oct 17]

5. Capurro S. Elastic neck lift in elderly patient. CRPUB Med Video J [Internet]. 2009. Available from: http://www.crpub.org/index. php?option $=$ com_k2\&view $=$ item\&id=51:09-elastic-neck-lift-inelderly-patients\&Itemid=114. [Last accessed on 2016 Oct 17]

6. Hwang K, Nam YS, Kim DJ, Han SH. Anatomy of tympanoparotid fascia relating to neck lift. J Craniofac Surg 2008;19:648-51.

7. Ellenbogen R, Karlin JV. Visual criteria for success in restoring the youthful neck. Plast Reconstr Surg 1980;6:26-37.

8. Kang MS, Shin JS, Nam SM, Park ES. Evaluation of elastic lift for facial rejuvenation. Arch Aesthetic Plast Surg 2016;22:20-7.

9. Kang MS, Kim SH, Nam SM, Park ES. Evaluation of elastic lift for neck rejuvenation. Arch Aesthetic Plast Surg 2016;22:68-73.

10. Stringer MD, Mirjalili SA, Meredith SJ, Muirhead JC. Redefining the surface anatomy of the parotid duct: an in vivo ultrasound study. Plast Reconstr Surg 2012;130:1032-7.

11. Huggins RJ, Freeman ME, Kerr JB, Mendelson BC. Histologic and ultrastructural evaluation of sutures used for surgical fixation of the SMAS. Aesthetic Plast Surg 2007;31:719-24. 